\title{
Tissue engineering in urethral reconstruction
}

\section{Altaf Mangera $^{1 *}$ and Christopher R Chapple ${ }^{1,2}$}

\author{
Addresses: ${ }^{1}$ Department of Urology Research, Sheffield Teaching Hospitals NHS Trust, Royal Hallamshire Hospital, Sheffield, S10 2JF, UK; \\ ${ }^{2}$ Sheffield Hallam University, 38-40 Howard Street, Sheffield, S1 1WB, UK \\ *Corresponding author: Atlaf Mangera (mangeraaltaf@hotmail.com) \\ FI000 Medicine Reports 2010, 2:65 (doi:10.3410/M2-65)
}

The electronic version of this article is the complete one and can be found at: http://fl000.com/reports/medicine/content/2/65

\begin{abstract}
Tissue engineering is an exciting and rapidly evolving technology. In this review, we discuss the recent progress made in the field of urethral reconstruction and consider the clinical implications and further advancement of these endeavours.
\end{abstract}

\section{Introduction and context}

The urethra serves as a conduit that allows urine to flow out of the bladder. In this review, we will discuss the development of tissue engineering to replace excised male anterior urethra. The anterior urethra represents the portion of the urethra extending from the external urethral meatus back to the distal end of the distal sphincter mechanism. The anterior urethra has a segmental blood supply with both a proximal and retrograde supply by way of the dorsal arteries, an important consideration when applying a living graft in need of sufficient vascular supply in order to survive. The anterior urethra is lined by a stratified columnar epithelium.

Tissue-engineered grafts have been used experimentally to treat disorders ranging from stricture disease to hypospadias deformity. The term 'urethral stricture' generally refers to anterior urethral disease or a scarring process involving the spongy erectile tissue of the corpus spongiosum. Urethral stricturing is a consequence of ischemic spongiofibrosis occurring within the urethra. Occasionally, a specific cause may be identified, although the majority of strictures are idiopathic.

Anterior urethral strictures are managed according to their size and position, commencing with the less invasive urethral dilatation, urethral stenting, or urethrotomy and progressing to anastomotic or substitution urethroplasty (or both). Tissue-engineered grafts are required for substitution urethroplasty. The substitution graft of choice is a full-thickness buccal mucosal graft because it is easy to harvest, tough, resilient, easy to handle, and picks up a blood supply very effectively [1]. It has a privileged immunology and fibroblast behaviour unlike that of skin and has less associated fibrosis.

In patients in whom a greater amount of mucosa needs to be harvested, labial (lip) and lingual (tongue) mucosa may also be harvested. The initial results using these are seen to be transposable to those seen with buccal mucosa [2-5]. The use of oral grafts is associated with numerous potential complications. Intraoperative haemorrhage, postoperative infection, pain and swelling, damage to salivary ducts, initial limited oral opening, altered sensation or numbness, scarring, and even deformity have been reported. However, in a survey of 295 patients, Barbagli et al. [6] found that $98.4 \%$ would undergo the surgery again despite the risk of complications.

\section{Recent advances}

Given the success of oral grafts, tissue-engineered grafts of the urethra are required only in cases of extensive stricture disease or in recurrent cases in which a previous oral graft was used. Therefore, a lot of this work remains within the realms of preclinical research. Clinicians have used unseeded and seeded (with cells) matrices in patients to fashion a new urethra.

el-Kassaby et al. [7] used acellular bladder matrix in nine patients with a healthy wound bed, with good results 
seen in eight of these patients, whereas in the six patients deemed to have a poor wound bed, only two had a good result, suggesting the importance of a healthy wound bed for use of the acellular bladder matrix graft. Palminteri et al. [8] used porcine small intestinal submucosa (SIS) as an acellular urethroplasty matrix, with $94 \%$ success in the short term, and Fiala et al. [9] reported $80 \%$ success rates at medium-term follow-up, whereas Hauser et al. [10] reported poorer results with acellular SIS grafts. Acellular grafts do not show promise in patients who have had failed urethroplasty or have a poor blood supply.

Given the varying success rates with acellular grafts, researchers have begun looking at the use of cell-seeded grafts. Cells obtained from the patient are multiplied in the laboratory and attached to a suitable matrix to be reimplanted in the patient. Results from cell-seeded grafts are awaited with much anticipation. The drawbacks of a cell-seeded graft are that it requires a period of cell culture in a cleanroom laboratory and that at present it is not suitable as an 'off the shelf' product. There are also cost and time implications. However, the cellular composition and mechanical properties of cell-seeded grafts can be approximated better to match urethral tissue.

Research in our own laboratory first reported on the use of tissue-engineered buccal mucosa implanted into humans [11]. We obtained fibroblasts and keratinocytes from oral mucosal biopsies and cultured these in the laboratory. The multiplied cells were then attached to a donor de-epidermised dermis and cultured at an air-fluid interface to produce a graft for implantation. Cell culturing techniques allow a virtually infinite amount of tissue to be produced with just one biopsy and this tissue may be used at many time points (for instance, if a repeat procedure was required). This is an important consideration in the cohort of patients in whom this technology may be used.

Our pilot clinical study [12] reported on five patients, all with extensive stricture disease secondary to lichen sclerosis. From the five patients, three have a patent urethra (at the time of writing), although all three required some form of instrumentation. The patients selected for our study were all complex and the outcomes must be placed in that context [13]. Moreover, it would not be ethical to extend this experimental application to patients with low-burden stricture disease.

Our tissue-engineered grafts were modelled upon buccal mucosa. The histological similarities may be seen in Figures $1 \mathrm{a}$ and $\mathrm{b}$. We noted that graft contraction and
Figure I. Hematoxylin and eosin histological sections of (a) buccal mucosa and (b) tissue-engineered buccal mucosa

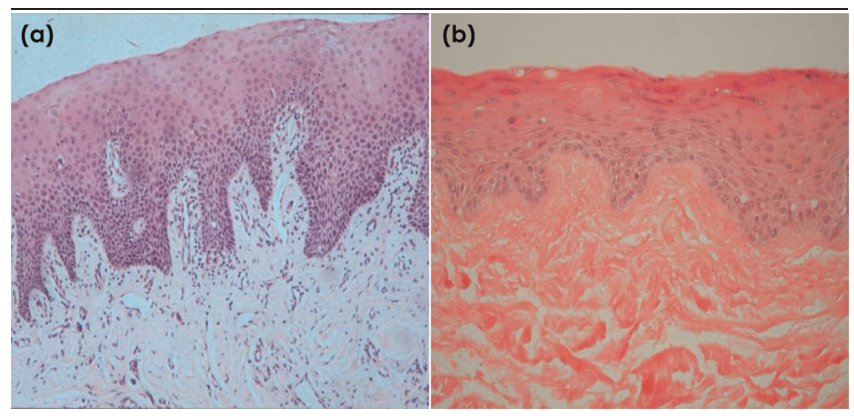

Magnifications, $\times 40$.

fibrosis occurred post-implantation and we are currently looking at techniques to overcome this. Whether the hyperinflammatory response was due to the lichen sclerosis or a reaction to the graft matrix is difficult to ascertain in this group of patients.

Recently, Fossum and Nordenskjold [14] described the use of autologous urothelial cells obtained from bladder washings to repair hypospadias deformity in a paediatric population. The cells were obtained from saline irrigation of the bladder and subsequently were expanded in the laboratory and finally returned to patients. Results were encouraging but the authors acknowledge that more work needs to be carried out to improve the tissueengineering techniques. Similarly, Nagele et al. [15] described a tissue-engineered multilayered urothelium expanded from bladder washings.

Currently, our work in the laboratory is concentrated on developing a scaffold that may be used to deliver the tissue-engineered graft and to reduce contraction and fibrosis occurring post-implantation. We are also looking at ways to manufacture sterile scaffold for clinical use [16]. Feng et al. [17], in a recent study of four different scaffold materials, assessed mechanical properties and cell attachment to the various seeded grafts.

Li et al. [18] described cellularisation of acellular bladder matrix grafts using autologous oral cells. This work has reached only the in vitro stage using rabbit oral mucosa cells, but the important finding is the biocompatibility of bladder acellular matrix with oral mucosa cells. Fu et al. [19] successfully attached foreskin epidermal cells on an acellular rabbit bladder matrix and proved this to be superior in terms of tissue organisation and re-stricturing compared with an unseeded acellular bladder matrix in a rabbit model. The same efforts to seed SIS with urothelial cells and subsequent culture, as attempted by Feil et al. [20], have been unsuccessful. 
In another avenue of research, Aboushwareb and Atala [21] described the promising approach of using adult progenitor stem cells or amniotic/placental stem cells to create new urethral tissue. However, this approach still requires much laboratory work. Given the ethical problems of using embryonic stem cells, much work has concentrated on obtaining stem cells from many different tissues, including bone marrow, striated muscle, fat, skin, and recently testicles.

\section{Implications for clinical practice}

The use of acellular bladder mucosa and SIS grafts has been trialled and has shown results comparable to the existing use of buccal mucosa in cases with a good wound bed. In these patients, an oral mucosal graft is most often sufficient. The necessity for a tissueengineered graft depends on whether a reduction in donor site morbidity is required and on the need for sufficient donor tissue.

The more pressing need for tissue-engineered grafts is in the treatment of long complex strictures, where the requirement for sufficient tissue imposes greater risk of complication from oral mucosal procedures. These patients tend to have a poor wound bed and make the design of the replacement graft more challenging. With this in mind, we are still searching for the ideal replacement graft. To this end, researchers are still in search of the optimum scaffold, seeded by the correct cells, which differentiate and repair without fibrosis. Scaffolds provide structural support and act as an extracellular matrix in which cell behaviour may be regulated. Therefore, the ideal scaffold should promote cell adhesion, proliferation, migration, and differentiation and have the appropriate biomechanical properties [22]. The appropriate cell must survive, proliferate, and differentiate into a cell capable of allowing the passage of urine without stimulating the inflammatory pathways to cause stricturing.

In conclusion, the reconstructive strategy used by the urologist for the treatment of the anterior urethra will depend on the extent of the disease, underlying pathology, availability of autologous grafts, and the underlying wound bed. With further improvements in seeding acellular matrices, the clinical use of tissueengineered materials is set to increase, especially in those most in need of it.

\section{Abbreviation}

SIS, small intestinal submucosa.

\section{Competing interests}

CRC has served as a consultant, participated in trials for, and has received speaker honoraria and research grants from Pfizer Inc. (New York, NY, USA) and Astellas (Tokyo, Japan), has served as a consultant for Novartis (Basel, Switzerland) and Ono Pharmaceutical Co., Ltd. (Osaka, Japan), has served as a consultant and participated in trials for Mitsubishi Tanabe Pharma Corporation (Osaka, Japan) and Recordati (Milan, Italy), and has received a speaker honorarium from Ranbaxy Laboratories Ltd. (Gurgaon, India). AM declares that he has no competing interests.

\section{Acknowledgments}

AM has received a fellowship from the Urology Foundation and the Robert Luff Foundation.

\section{References}

I. Fransis K, Vander Eeckt K, Van Poppel H, Joniau S: Results of buccal mucosa grafts for repairing long bulbar urethral strictures. BJU Int 2009, [Epub ahead of print].

2. Castagnetti M, Rigamonti W: Aptness and complications of labial mucosa grafts for the repair of anterior urethral defects in children and adults: single centre experience with II 5 cases. World J Urol 2009, [Epub ahead of print].

3. Das SK, Kumar A, Sharma GK, Pandey AK, Bansal H, Trivedi S, Dwivedi US, Bhattacharya V, Singh PB: Lingual mucosal graft urethroplasty for anterior urethral strictures. Urology 2009, 73:105-8

4. Barbagli G, De Angelis M, Romano G, Ciabatti PG, Lazzeri M: The use of lingual mucosal graft in adult anterior urethroplasty: surgical steps and short-term outcome. Eur Urol 2008, 54:67I-6.

5. Simonato A, Gregori A, Ambruosi C, Venzano F, Varca V, Romagnoli A, Carmignani G: Lingual mucosal graft urethroplasty for anterior urethral reconstruction. Eur Urol 2008, 54:79-85.

FI000 Factor 3.3 Recommended

Evaluated by Kenneth Angermeier I I Aug 2008, Guido Barbagli 03 Sep 2008, Carlos Giudice 04 Jan 2010

6. Barbagli G, Fabbri F, Romano G, De Angelis M, Lazzeri M: Evaluation of early, late complications and patient satisfaction in 300 patients who underwent oral graft harvesting from a single cheek using a standardised technique in a referral center experience. J Urol 2009, I8I(Suppl 4): I4.

7. el-Kassaby A, Aboushwareb T, Atala A: Randomized comparative study between buccal mucosal and acellular bladder matrix grafts in complex anterior urethral strictures. J Urol 2008, I79:|432-6.

8. Palminteri E, Berdondini E, Colombo F, Austoni E: Small intestinal submucosa (SIS) graft urethroplasty: short-term results. Eur Urol 2007, 51:1695-701.

FI000 Factor 3.0 Recommended

Evaluated by Hunter Wessells 07 Jan 2008

9. Fiala R, Vidlar A, Vrtal R, Belej K, Student V: Porcine small intestinal submucosa graft for repair of anterior urethral strictures. Eur Urol 2007, 5 I:1702-8.

10. Hauser S, Bastian PJ, Fechner G, Muller SC: Small intestine submucosa in urethral stricture repair in a consecutive series. Urology 2006, 68:263-6.

II. Bhargava S, Chapple CR, Bullock AJ, Layton C, MacNeil S: Tissueengineered buccal mucosa for substitution urethroplasty. $B J U$ Int 2004, 93:807-II.

12. Bhargava S, Patterson JM, Inman RD, MacNeil S, Chapple CR: Tissueengineered buccal mucosa urethroplasty-clinical outcomes. Eur Urol 2008, 53:1263-9. 
13. Watkin N: Editorial comment on: tissue-engineered buccal mucosa urethroplasty-clinical outcomes. Eur Urol 2008, 53:|270-I.

14. Fossum M, Nordenskjold A: Tissue-engineered transplants for the treatment of severe hypospadias. Horm Res Paediatr 2010, 73:| $48-52$.

15. Nagele U, Maurer S, Feil G: A new option for urethral reconstruction with multilayered urothelium established from bladder washings. Eur Urol Suppl 2006, 5:47.

16. Selim M, Bullock AJ, MacNeil S, Chapple CR: Evaluation of sterilisation methods on biological and mechanical properties of a synthetic biodegradable electrospun scaffold for the creation of tissue engineered buccal mucos for clinical use. Eur Urol Suppl 2009, 8:185.

17. Feng C, Xu YM, Fu Q, Zhu WD, Cui L, Chen J: Evaluation of the biocompatibility and mechanical properties of naturally derived and synthetic scaffolds for urethral reconstruction. J Biomed Mater Res A 2010, 94:3 I7-25.
18. Li C, Xu Y, Song L, Cui L, Yin S: [A preliminary experimental study on urethral reconstruction using tissue engineered oral mucosa]. Zhongguo Xiu Fu Chong Jian Wai Ke Za Zhi 2008, 22:1242-5.

19. Fu Q, Deng CL, Liu W, Cao YL: Urethral replacement using epidermal cell-seeded tubular acellular bladder collagen matrix. BJU Int 2007, 99: I 162-5.

20. Feil G, Christ-Adler M, Maurer S, Corvin S, Rennekampff HO, Krug J, Hennenlotter J, Kuehs U, Stenzl A, Sievert KD: Investigations of urothelial cells seeded on commercially available small intestine submucosa. Eur Urol 2006, 50:1330-7.

21. Aboushwareb T, Atala A: Stem cells in urology. Nat Clin Pract Urol 2008, 5:62|-3I.

22. Aboushwareb $T$, Atala $A$ : Regenerative medicine for the urethra. In Biomaterials and Tissue Engineering in Urology. Edited by Atala A. Cambridge, UK: Woodhead Publishing Limited; 2009:454-464. 